\title{
O corpo pode ser sujeito? Nota sobre Merleau-Ponty
}

\section{Luiz Damon Santos Moutinho}

Professor, Departamento de Filosofia, Universidade Federal de São Carlos - UFSCar, São Carlos, SP, Brasil.

Resumo: O artigo discute, no âmbito de uma ampla "reabilitação do sensível", o resgate merleaupontiano do corpo como peça nuclear do sistema. E põe como questão central o seguinte: pode o corpo, anônimo e impessoal, ser efetivamente um sujeito?

Palavras-chave: Merleau-Ponty; corpo; sujeito. 
Para responder a essa questão, começo traçando rápido paralelo entre Sartre e Merleau-Ponty, lembrando que essa questão se coloca com alguma pertinência para o segundo, não para o primeiro. Mas o paralelo nos ajuda a compreender o que exatamente Merleau-Ponty combate com a reabilitação do corpo. O paralelo é bom porque ambos os autores, partindo de Husserl, se alimentam de um mesmo projeto de combate ao primado da epistemologia e do sujeito de conhecimento, ambos buscam dar novo sentido ao conceito de experiência, alargando sua acepção meramente cognitiva (a experiência é também estética, social, religiosa, afetiva etc), ambos buscam, enfim, falar filosoficamente do existente e da experiência concreta, buscando reconhecer o que a experiência tem de metafísica.

Para se resgatar, em Sartre, algum sentido para o "sujeito", é preciso opor consciência e ego, como ele faz logo de saída. A consciência sartriana é sem ego, sem identidade; e o ego, por sua vez, aparece como uma ficção, ficção bem fundada, é certo, na medida em que é o produto de uma reflexão que, voltando-se para o ato de consciência, constitui o ego para além desse ato como polo de todos os atos; mas, ainda assim, é uma ficção, produzida no momento mesmo da reflexão - o que significa dizer que ele só é enquanto ela durar. O sentido dessa constituição consiste em dar unidade ao fluxo de experiências na forma de uma "psique", e por isso mesmo o ego é constituído como um objeto permanente que não passa com o fluxo: o ego é uma criação tardia. Antes, portanto, dessa reflexão criadora e impura, há uma experiência originária, espontânea e irrefletida do homem no mundo, e, para alcançá-la, é preciso métodos especiais capazes de nos abrir esse campo "subjetivo". Essa oposição entre consciência (o verdadeiro sujeito?) e ego prepara igualmente uma distinção entre o território da filosofia e o da psicologia (o do ego objeto psíquico).

Nesse plano originário, a consciência é fato, não um conjunto de condições lógicas à maneira da filosofia transcendental. Ela é, mais precisamente, existencial. Por isso mesmo, a relação ao mundo não será do tipo sujeito-objeto, não será uma relação de conhecimento: antes de ser cognitiva, diz Sartre, a consciência "existe". Mas ela não existe em separado, ela não será nem mesmo metodologicamente, por reflexões especiais, separável do mundo: a relação ao mundo perfaz uma totalidade que não se deixa separar sem cair em abstração. E porque essa relação não é cognitiva, tampouco o ser para o qual ela se volta é "ser conhecido", "ser percebido", ou "objeto". Sartre distingue o plano do objeto como plano "lógico" do plano ao qual a boa reflexão deve nos levar, que é o do "ser", ou "ontológico". Ora, o que vai marcar propriamente a novidade de Sartre, aquilo que vai singulariza-lo, é a complexa tese de que a consciência, sendo relação inseparável a transcendência, é relação a outra coisa que ela mesma, relação a uma alteridade na forma de não ser isso para que ela está voltada; não sendo isso para que ela está voltada, ela própria se faz testemunha disso, de ser relação àquilo que ela não é; ela é então negação daquilo de que ela é consciência, e só assim ela se afirma como consciência de. Essa negação parte dela. Não é do tipo da negação que diz: essa cadeira não é a mesa. Nesse caso, a relação é testemunhada por um terceiro. A consciência é consciência de não ser isso para que ela está voltada. O tertius é ela mesma, e isso define a estrutura "consciência".

Em movimento análogo, também Merleau-Ponty busca a experiência originária, anterior às ficções - legítimas ou não - que são lançadas sobre ela. Também para ele há uma duplicidade entre o território propriamente fenomenológico e o território derivado ou segundo, aquele em que o "sujeito" é objetivado e o mundo é um em si dado. Mas é um outro aspecto que Merleau-Ponty revela: ele não opõe seu "sujeito" 
a um ego ficcional, mas à própria ideia de pessoalidade implicada pela consciência (por qualquer consciência, sartriana ou não) ${ }^{1}$. Daí porque o sujeito merleau-pontiano é o corpo, não a consciência, daí porque Merleau-Ponty dirá que o seu "sujeito" é anônimo, impessoal. Nesse caso, o corpo percebe o mundo autonomamente, sem o recurso a uma consciência, o corpo é, nele mesmo, cognoscente, dotado de intencionalidade. Quando um mosquito pica minha perna, por exemplo, minha mão vai diretamente ao ponto picado sem que seja necessário um cálculo, uma disposição do meu corpo no espaço e a instrução, por parte da consciência, do movimento a ser feito pela minha mão; ao contrário: minha mão sabe onde está o ponto, sabe que movimento deve ser feito, meu corpo é cognoscente. O corpo é movimento, é carne, mas não é movimento cego, não é mecanismo, não é um autômato.

Dizer que ele é cognoscente não é dizer que ele tem a representação dos fins visados por ele; esse saber não é da ordem da representação, não é intelectual; é um saber corporal. O corpo sensível é um corpo senciente. Ora, é esse o "sujeito" o mais originário, aquele que percebe o mundo, que significa o mundo; é a experiência corpórea do mundo a experiência mais originária, primitiva, mais fundamental. É certo que também para Merleau-Ponty, tal como para Sartre, os sentidos do mundo são "subjetivos", e qualquer comentário do mundo tem que pressupor um tal "sujeito", como um espinho cravado na garganta. No entanto, o "sujeito" merleaupontiano é essa carne sensível, de modo que os significados do mundo devem ser pensados por referência a ele.

\section{II}

Daqui decorrem duas diferentes teses sobre a liberdade. Para Sartre, a verdadeira liberdade será desvelada se cavarmos para além do Ego, desse "sujeito" identitário que, uma vez definido, é posto diante de alternativas e escolhe. Aqui também é preciso recuar: o "sujeito" não está constituído, mas também não o mundo - o que implica dizer que é preciso recuar a uma situação em que o próprio mundo se faz na medida mesma em que ele é significado por mim dessa ou daquela maneira; a verdadeira escolha, uma vez que nos coloquemos nesse território originário em que nem o sujeito, nem o mundo, estão dados, não é a escolha entre predicados dados, é aquela em que os próprios predicados são "escolhidos" por mim, significados por mim. Por aqui, Sartre pretende dizer que os sentidos do mundo não são coisas dadas, neutras, objetivas, mas sentidos "subjetivos", de tal modo que o próprio predicado "escalável" ou "não escalável" do rochedo só é tal, "escalável" ou "não escalável", à luz de um projeto meu. Se há um rochedo que eu não posso escalar, isso não quer dizer que eu não sou livre, que ele é um entrave a minha liberdade. Dizer que sou livre apenas se me for possível escalar o rochedo é me colocar no terreno segundo, das coisas já dadas, com predicados dados, e cuja origem não se sabe de onde vem. A reflexão radical, para além daquela que a psicologia realiza, é a reflexão que busca o originário e, a essa luz, o próprio predicado "escalável" só é tal à luz de meu projeto que significa o mundo. $\mathrm{O}$ insucesso da minha empreitada - não conseguir escalar o rochedo - não me torna não livre. O homem não deixa de ser livre se não tem êxito. É certo que, da perspectiva de Merleau-Ponty, o rochedo não seria "inescalável" se não houvesse "sujeitos", mas ele é inescalável para o corpo, para esse "eu natural", não para uma consciência. Que isso muda?

Digamos que a mudança vai consistir em retirar do "sujeito" uma centralidade, um imperialismo, pelo qual uma consciência soberana dá sentidos ao mundo,

\footnotetext{
1 - A consciência sartriana, por não ser egóica, nem por isso é anônima; ela é antes "não substancial". Cf. Sartre. L'être et le néant. Paris : Gallimard, 1943, p. 148; 209.
} 
reconhecendo, ao contrário, nesse "sujeito" uma certa passividade que Sartre não pode reconhecer justamente porque toma o "sujeito" como consciência. O corpo descentra a consciência soberana, retira dela o centro da ação, torna-a excêntrica. Em termos de intencionalidade, tudo se passa como se Sartre não reconhecesse senão a "intencionalidade de ato", essa intencionalidade tética e centrífuga que brota da consciência em direção ao mundo. Merleau-Ponty, ao contrário, fala de uma "intencionalidade de horizonte", ou "noemática", essa que habita o mundo sensível ligando as partes umas às outras em um mesmo "todo" e tornando-o "expressivo", configurando-o como um "campo". Daí porque projetos "pessoais" como o de escalar esse rochedo nascem a partir desse campo, enraizados nele, e do qual meu corpo é parte. A passividade advém daí, dessa significação do sensível que, se envolve o meu corpo, não foi ele que a constituiu.

Daí porque Merleau-Ponty pode dizer que ele busca uma "adesão" à experiência, ao invés de fazer "o mundo repousar na atividade sintética do sujeito", o que se traduz em um recurso a um "sujeito" naturante que possuiria o segredo do mundo. Assim, a tarefa da "redução fenomenológica", que é o nome técnico daquele "recuo" de que falamos (em Sartre, ele se chama "reflexão pura"), é o de explicitar a unidade do mundo, unidade que está aí antes de qualquer análise: a unidade do mundo é "primordial", isto é, ela não deriva de uma série de sínteses; o real, diz Merleau-Ponty, é "um tecido sólido, ele não espera nossos juízos para anexar a si os fenômenos mais aberrantes, nem para rejeitar nossas imaginações mais verossímeis" ${ }^{\prime 2}$. A unidade do mundo não é resultado de uma constituição, ela está aí sem que eu tenha que costura-la: "o mundo não é um objeto do qual possuo comigo a lei de constituição". A síntese do mundo é autóctone, é anterior a todo pensamento que eu possa forjar dele. É preciso pois inverter a "inversão copernicana" de Kant e mostrar que Kant, ele sim, supõe todo o tempo nossa relação ao mundo, que, portanto, sua reflexão, não é suficientemente radical, na medida em que o mundo é já esse meio prévio e, como tal, o "campo de todos os meus pensamentos e de todas as minhas percepções explícitas". Nossa relação ao mundo torna-se assim, para Merleau-Ponty, o "motor da dedução transcendental". Inverter Kant vai significar então fundar o possível no real, como o pensamento no mundo, e não o real no possível, fazendo do mundo uma idealidade ${ }^{3}$. Diante disso, o projeto de Merleau-Ponty é bem mais que recuperar o corpo como "sujeito" impessoal da percepção; ele busca antes resgatar o logos do mundo sensível, de que o corpo é parte.

\section{III}

Assim, enquanto a reflexão merleaupontiana vai na direção a esse mundo pré-organizado, cujo sentido é autóctone, a reflexão sartriana vai em direção à consciência enquanto negatividade, como relação a outra coisa que ela mesma, como negação dessa coisa. Correlativamente, poderíamos dizer que o mal passo da reflexão seria, da perspectiva de Merleau-Ponty, voltar a um sujeito que faça a síntese do mundo; para Sartre, ao contrário, seria a reflexão que nos levasse a uma consciência "continente", uma consciência com conteúdos de consciência, representacional, portanto, e de que o ego seria o limite. Tomemos o célebre exemplo cartesiano do pedaço de cera para figurar essa diferença. A censura de Sartre a esse modelo de reflexão consiste em tornar a cera um "conteúdo" de consciência, o que torna consciência um continente e a espacializa. A consciência não seria relação direta ao

\footnotetext{
2 - Merleau-Ponty. Phénoménologie de la perception. Paris : Gallimard, 1995, p. V (Ed. bras. Fenomenologia da percepção. Trad. Carlos Alberto Ribeiro de Moura. São Paulo : Martins Fontes, 1996, p.6).

3 - Idem, p.VIII (10); p.XII (14).
} 
mundo, a essa transcendência que ela não é, mas a seus próprios conteúdos. O mundo se dissolve em conteúdos de consciência, numa "baba" de um espírito-aranha que tudo arrasta para sua teia. Sartre dirá então: o primeiro ato filosófico é voltar ao cogito, mas desde que ele nos leve para além dele, o que traduz precisamente essa consciência voltada a uma alteridade e que é consciente de sê-lo.

Para Merleau-Ponty, por sua vez, que pretende retomar um sentido do próprio material sensível, trata-se antes de apontar como as partes do sensível se organizam em um todo expressivo, como estão intimamente ligadas umas às outras, de modo que cada parte anuncia mais do que aquilo que ela contém. Assim, a cor mate dessa cera percebida anuncia a moleza, a moleza anuncia o som, cada perfil anuncia outro perfil e assim sucessivamente. A cera cartesiana, desse ponto de vista, é a cera do físico, é um resíduo físico da variação sensível, definida então como fragmento de extensão: "a célebre análise do pedaço de cera salta de qualidades como o odor, a cor e o sabor para a potência de uma infinidade de formas e de posições, que está para além do objeto percebido e só define a cera do físico"

Para Sartre, o problema está na interiorização do sensível; para Merleau-Ponty, está na desqualificação do sensível, e, por isso mesmo, na exigência correlata de um sujeito autor da síntese do mundo. O passo cartesiano, com seu experimento de variação sensível, consistiu naquela desqualificação, e por isso ele faz da percepção uma "inspeção do espírito"; analogamente, é o que faz Kant quando parte de um "diverso sensível" - "diverso", isto é, sem organização, organizado apenas pelas formas transcendentais. O problema maior então, para Merleau-Ponty, consiste na dissociação entre o sensível e o inteligível, no não reconhecimento de um logos sensível.

Sendo assim, parece que, ao recusar o sujeito autor da síntese, e afirmando, contra isso, a autonomia do sensível, Merleau-Ponty quer em verdade afastar o sujeito do idealismo. Se, por outro lado, ao afirmar o logos sensível, nem por isso ele se coloca como empirista (também no empirismo o sensível é desprovido de sentido autóctone, e se não há ali um sujeito que se afirme no começo como fonte do sentido, há, por outro lado, princípios de associação que devem igualmente responder pela organização do sensível), se há ali então um "sujeito", alguém de perfil sartriano poderia cobrar: me diga então que "sujeito" é esse, que está lá sem ser tardio, sem ser constituído por princípios de associação, e, por outro lado, está lá sem comprometer o caráter autóctone do sentido, sem produzir o sentido, como o sujeito do idealismo.

Ora, o "sujeito" merleaupontiano não pode ser "intelectual", não pode ser uma consciência. A posição de uma consciência implica, a fortiori, em um desequilíbrio: se ele é sujeito, diante dele só pode haver objeto. A necessidade em que se encontra Merleau-Ponty é então a de afirmar não só o caráter autóctone do sentido, mas, ao mesmo, tempo afirmar um "sujeito" para quem esse sentido é sentido. O sentido é do mundo, certamente, mas ele é, também, sentido, isto é, implica uma perspectiva. A solução é tornar o corpo um tal "sujeito". Pois o corpo, por ser igualmente sensível, não é estranho ao mundo, responde a ele sem ser anulado por um terceiro extramundano.

\section{IV}

Ora, mas essa solução não pode ser senão provisória. Pois é preciso ainda se perguntar o que faz o vínculo entre corpo e mundo. Dizer que corpo e mundo são igualmente sensíveis é postular uma identidade não tematizada. E isso ainda não responderia à questão do sentido: de onde vem que o sensível seja expressivo? A resposta a essas questões permite finalmente compreender porque, ao falar do "sujeito" merleaupontiano, vínhamos grafando-o com aspas. É que, para além do

${ }^{4}$ - Idem, p.41 (61). 
corpo e do mundo, há um terceiro elemento que responde às duas questões acima. Esse elemento é o tempo. De um lado, corpo e mundo são "sincronizados" pelo tempo, postos em "comunhão" um com o outro, vinculados um ao outro. De outro lado, é a eterna passagem do tempo, é o eterno movimento para adiante, o lançar-se sempre para fora, para além, que é a gênese do sentido: se esse perfil se vincula àquele perfil, se essa relação os torna expressivos, é porque cada perfil só existe enquanto anuncia o outro e vice-versa. Essa expressividade deve ser então tomada em sentido temporal: os perfis não presentemente percebidos por mim estão também aí e fazem parte do largo campo de presença como quase presentes, o que significa dizer que eles estão aí como passado e como porvir, isto é, que eles são temporais. É o tempo que tece o logos do sensível. Assim, não é de modo algum o corpo, ou uma consciência acima dele (o que o anularia), que prospecta o porvir e retém o passado, é o tempo que alarga o campo de presença, é ele que anuncia horizontes. Corpo e mundo - ou melhor, a totalidade corpo-mundo-outrem -é um todo temporalizado. É porque esse todo é temporal, é por isso que o corpo percebe sempre além do aspecto presente, e não porque um "para si", distinto do ser como em Sartre, prospectaria um porvir e reteria o passado. Se o corpo pode então responder a um sentido do mundo, como se formasse um com ele, é porque ele acompanha um movimento que é do próprio Ser. O tempo é a medida do Ser, não a forma da consciência.

Assim, bem feitas as contas, o corpo não pode ser sujeito. E por sujeito se entenda aqui um polo que se afirme como fonte de significação. Mesmo que esse polo não seja pessoal, ele é ainda um centro, e como tal ele bloqueia algo que é essencial à tese merleaupontiana de que o sentido é do mundo: uma despossessão. Não por outra razão, Merleau-Ponty se interessa tanto pelos fenômenos de despersonalização e patologias. É que, no limite, apenas o corpo pode alucinar, enlouquecer, despersonalizar-se, ser literalmente tomado, apenas ele é aberto a essa possibilidade, não a consciência - portanto, apenas ele pode ser atravessado por um sentido que não vem dele. Em Sartre, essa impossibilidade é vista com clareza, pois para ele apenas a pessoa enlouquece, não a consciência: o cogito não é jamais destituído. Ora, isso é inaceitável para Merleau-Ponty: a loucura será justamente a perda desse centro. Dizer que o corpo não é sujeito, é então, para Merleau-Ponty, dizer que o corpo não se põe como centro, que ele não é "autor" do sentido, que ele pode se abrir a um sentido vindo do mundo. Ora, mas aqui é necessário frisar: também Sartre rejeita que sua consciência espontânea seja sujeito (por isso, vínhamos também grafando-o com aspas). Nesse caso, não pelas mesmas razões que Merleau-Ponty, que vê a consciência sartriana, apesar dos protestos, como sujeito, mas porque sua consciência é não substancial: Sartre pensa sujeito como substância, como um permanente; Merleau-Ponty, ao contrário, pensa sujeito como fonte de significação.

Ora, mas se é assim para Merleau-Ponty, se o sujeito é a fonte de sentido, e se é o tempo quem tece a trama da expressividade, então é preciso admitir que o tempo faz agora as vezes do sujeito. E, de fato, é assim que Merleau-Ponty o apresenta no capítulo decisivo da Fenomenologia da percepção, "A temporalidade". Tratar-se-ia, no final das contas, de simplesmente substituir um sujeito por outro? Mesmo que se trate de um sujeito inédito, apenas homônimo àquele clássico, rejeitado sob a rubrica de "idealismo", é ainda nos limites de uma "filosofia do sujeito" que se moveria o pensamento de Merleau-Ponty. É certo que o tempo é sujeito ek-stático, isto é, sujeito que só existe "fora de si", como fuga geral para fora de si, mas isso não mudaria o essencial: o brotamento do sentido em um sujeito. Não é aqui o lugar para desenvolver o tema da temporalidade ${ }^{5}$. Basta notar que esse sujeito não faz brotar um sentido à maneira de uma consciência ou de um demiurgo: ele não é constituinte,

\footnotetext{
5 - Permito-me a liberdade de enviar o leitor para o meu “Tempo e sujeito. O transcendental e o empírico na fenomenologia de Merleau-Ponty" in DoisPontos, 2004, v.1, n.1.
} 
não é transcendental no sentido ordinário da palavra. Para que um sentido advenha ao mundo, é preciso ainda o concurso do próprio mundo, isto é, do sensível: o sentido só existe como sentido encarnado. Esse tema, presente desde o início, e que está por trás da mais ampla reabilitação do sensível, vai orientar o pensamento de Merleau-Ponty em outra direção, na direção de uma nova figura do logos, do que ele chama o "logos sensível". Portanto, mesmo ali onde Merleau-Ponty ainda mantém o vocabulário clássico do sujeito - logo fadado ao abandono -, é preciso cautela: o sujeito de que aqui se fala não converte o pensamento de Merleau-Ponty em uma "filosofia do sujeito", tema que, de modo apressado, Foucault lançou contra ele. Mas esse é um tema para outro ensaio.

*Correspondência: Departamento de Filosofia, Universidade Federal de São Carlos - UFSCar, Rodovia Washington Luís, Km 310, São Carlos - SP, Brasil. E-mail: luizdamon@yahoo.com.br Conflito de interesses: nenhum.

Todos os autores leram e aprovam a versão final submetida a revista Em curso. 